\title{
A new approach to selecting Marine Protected Areas (MPAs) in the Southern Ocean
}

\author{
JANE HARRIS $^{1 *}$, MARCUS HAWARD ${ }^{1,2,3}$, JULIA JABOUR ${ }^{1,2}$ and ERIC J. WOEHLER ${ }^{1,4}$ \\ ${ }^{1}$ Institute of Antarctic and Southern Ocean Studies, University of Tasmania, Private Bag 77, Hobart, TAS 7001, Australia \\ ${ }^{2}$ Antarctic Climate and Ecosystems Cooperative Research Centre (ACE CRC), University of Tasmania, Private Bag 77, Hobart, TAS 7001, \\ Australia \\ ${ }^{3}$ School of Government, University of Tasmania, Private Bag 77 Hobart, TAS 7001, Australia \\ ${ }^{4}$ Australian Antarctic Division, Channel Highway, Kingston, TAS 7050, Australia \\ *Corresponding author: jwharris@utas.edu.au
}

\begin{abstract}
Conservation of the high seas marine environment poses a significant challenge to policy-makers and managers. Marine conservation efforts are often hindered by the lack of data and the difficulties in addressing multiple, and typically conflicting uses. The majority of extant Marine Protected Areas (MPAs) are in coastal or tropical regions within national jurisdiction. Conservation of high seas MPAs has emerged on the international agenda as a critical issue requiring the application of novel approaches, international cooperation and political will. Knowledge and understanding of the marine environment and data on marine biodiversity are all typically limited for the high seas, and the use of surrogates to assist in the identification of areas of high conservation value is one possible mechanism to address and potentially overcome these limitations. Drawing upon a database spanning more than 20 years and containing approximately 140000 records of seabird sightings at sea, this study assesses the potential use of seabirds as surrogates for marine biodiversity in the Indian sector of the Southern Ocean. At-sea ranges, species diversity and the distributions of endangered species may be appropriate selectors or filters to identify areas with high conservation values. Integrating policy with science provides an appropriate mechanism to identify and prioritise MPAs in the Southern Ocean.
\end{abstract}

Received 4 March 2006, accepted 20 March 2007

Key words: Antarctic, biodiversity, conservation, protected area system, seabirds

\section{Introduction}

The Antarctic Protected Area system has developed in an ad hoc manner since the early 1960s, and recently the need to develop a systematic and representative marine protected area (MPA) system has been acknowledged as an emergent issue requiring broad attention (Kelleher et al. 1995, Gjerde \& Breide 2003, CCAMLR 2005). A major issue facing decision makers regarding Southern Ocean marine conservation is the paucity and patchiness of marine biological data. Sampling coverage is often patchy and unrepresentative in both time and space, and also in terms of species biodiversity, distribution and abundance. Although the oceans cover $70 \%$ of the Earth's surface (Dallmeyer 2003), of which $50 \%$ is high seas (Gjerde \& Breide 2003), global knowledge of the species inhabiting the marine environment is depauperate, with estimates of marine species to be discovered ranging from 178000 species to around 10 million (Sala \& Knowlton 2006). The question remains, then, how do we select areas for conservation action in the absence of full scientific knowledge on global marine biodiversity, and in particular in the high seas?

Here we assess the use of seabird at-sea sightings to act as surrogates for marine biodiversity, and to assist in the identification and selection of priority areas for consideration for conservation and management in the
Southern Ocean. Seabirds at-sea are among the most advanced marine datasets (albeit still patchy in time and space), and thus offer opportunities for assessing and identifying potential MPAs for conservation purposes. The at-sea distribution of seabirds is typically dependent upon prey availability, which is influenced by the geographical distribution, abundance and accessibility of prey species and physical and biological oceanographic factors (e.g. Hunt 1991, Ainley et al. 1993, Woehler 1997, Woehler et al. 2003, Bradshaw et al. 2004). In the Antarctic, seabird breeding distributions are largely constrained due to the limited amount of suitable ice free areas (e.g. Woehler 1990, Hunt 1991). Seabird sightings have value for conservation planning as they are typically actively recorded during marine surveys (so can be considered presence/absence data since observations of no seabird sightings are recorded), seabirds are conspicuous, and areas with high numbers of seabird species have been found to have high numbers of other species (Brooks et al. 2001, Garson et al. 2002, Margules et al. 2002).

\section{Methodology}

A seabird at-sea for the period 1977/78 to 2001/02 excluding 1981/82 (Watts \& Woehler 2003) was used. The 
database comprised 137417 records of seabird at-sea sightings collected during marine research or Antarctic resupply voyages. Full details of methods used to collect and analyse these data are presented elsewhere (see Woehler 1997 and Harris 2006, respectively). Briefly, the study area was the Southern Ocean south of $40^{\circ} \mathrm{S}$ to the Antarctic Continent, and between $45^{\circ}-160^{\circ} \mathrm{E}$, where the majority of observations were made ( $n=136052$ records, 99\%). To check for possible artefacts arising from the spatial scales used for analyses, the data were binned into three arbitrarily-chosen bin sizes of $1^{\circ}$ lat x $1^{\circ}$ long $(n=1952$ records), $2^{\circ}$ lat $\times 2^{\circ}$ long ( $n=704$ records), and $5^{\circ}$ lat $\times 5^{\circ}$ long ( $n=177$ records), as used by Raymond \& Woehler (2003). The use of spatial bins allowed data to be aggregated, or summarized, to standard spatial scales and enabled direct comparisons to be made among areas and their characteristics. At each scale, four indices or measures were calculated:

Species density: the abundance of species (i.e. total[number of] seabird species observed.

Species richness: the number of individual seabird species

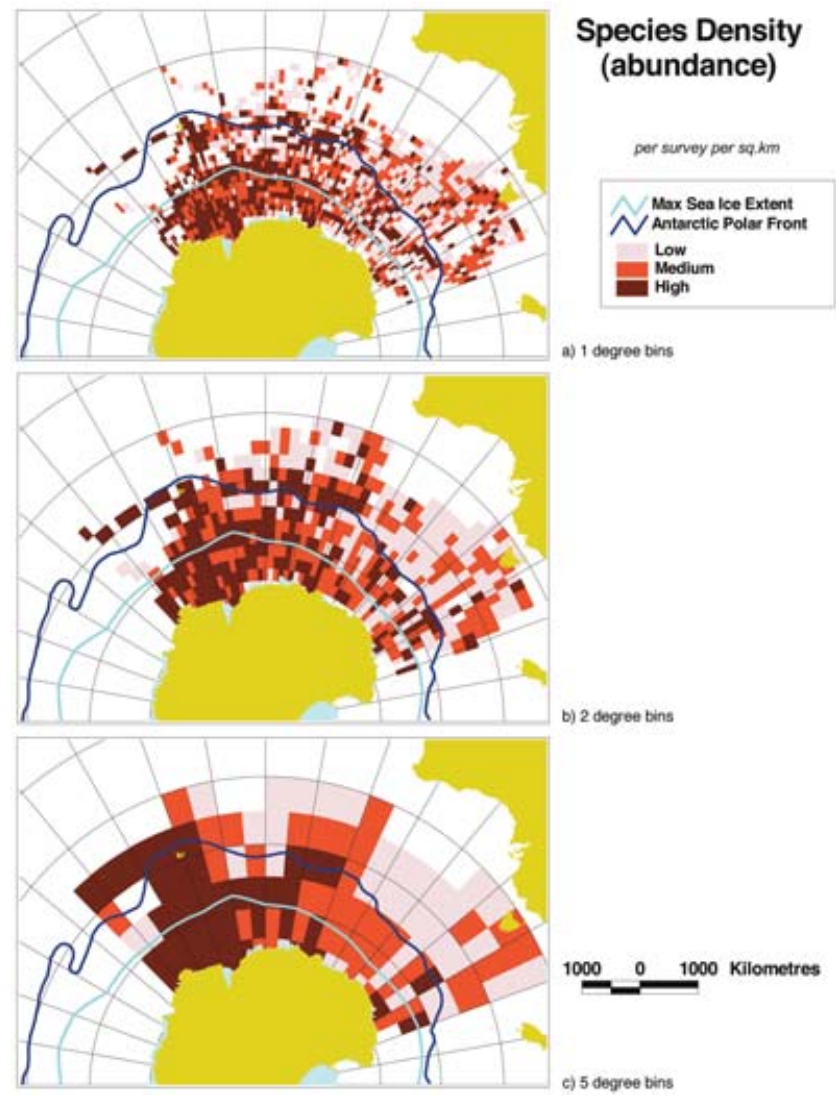

Fig. 1. Species density (number of birds $/ \mathrm{km}^{2} /$ survey) at $1^{\circ} \times 1^{\circ}, 2^{\circ}$ $\mathrm{x} 2^{\circ}$ and $5^{\circ} \times 5^{\circ}$ latitude $\mathrm{x}$ longitude, classified as low (pink), medium (red) and high (maroon) for the Indian sector of the Southern Ocean for the period 1977/78 to 2001/02.
IUCN conservation status: abundance(s) of Endangered or Vulnerable seabird species (as per World Conservation Union (IUCN) conservation status; see www.redlist.org, as at November 2004)

Shannon Index: a measure that combines seabird species density and distribution

Values of each of the four measures within each bin were fractioned as a proportion of the surveys undertaken and area per bin (e.g. density per survey per $\mathrm{km}^{2}$ ) and then normalized between 0 and 1 . Each measure was classed into one of three classing sets: low, medium and high, and mapped for each bin size. The areas of greatest interest for potential conservation action and management are those classed high for species density, richness and IUCN status. The Shannon Index was not used for plotting (see Results).

\section{Results}

Seabird species density

Species density for seabirds in the Indian sector of the Southern Ocean for the period 1977/78 to 2000/01 is shown in Fig. 1. The regions that were characterized by high

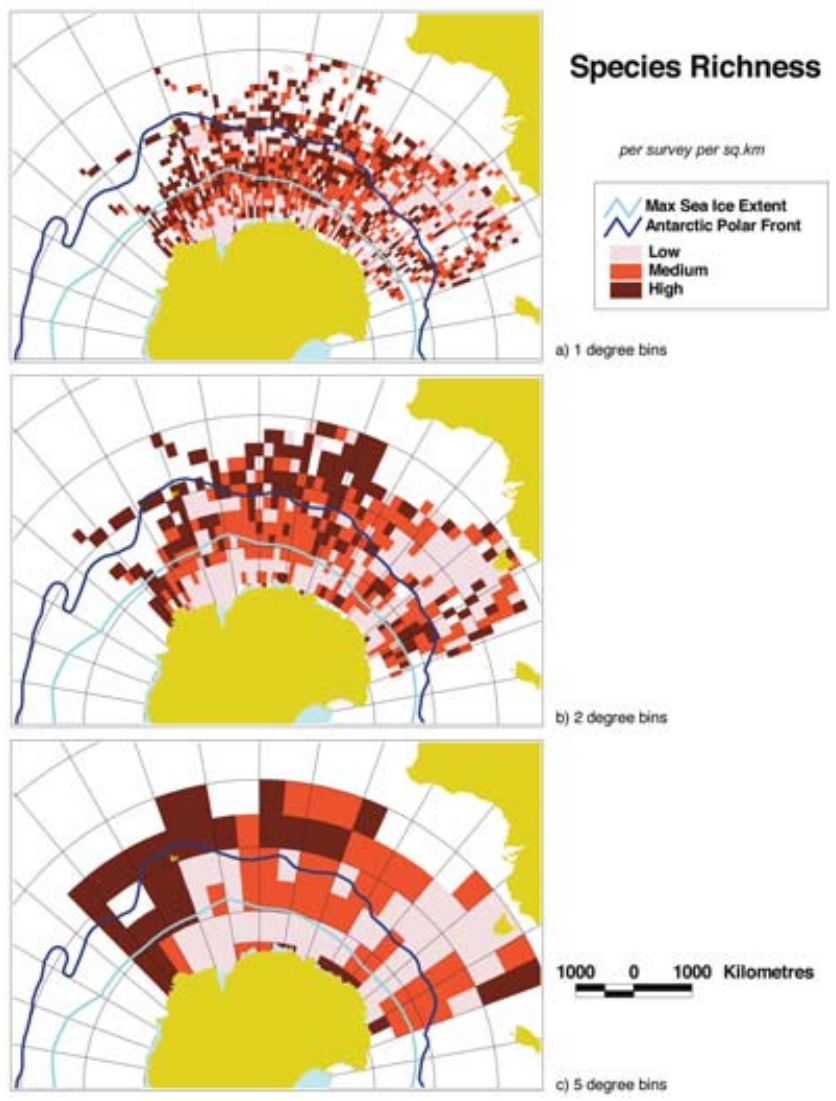

Fig. 2. Species richness (number of bird species $/ \mathrm{km}^{2} /$ survey) at $1^{\circ}$ $\times 1^{\circ}, 2^{\circ} \times 2^{\circ}$ and $5^{\circ} \times 5^{\circ}$ latitude $\mathrm{x}$ longitude, classified as low (pink), medium (red) and high (maroon) for the Indian sector of the Southern Ocean for the period 1977/78 to 2001/02. 


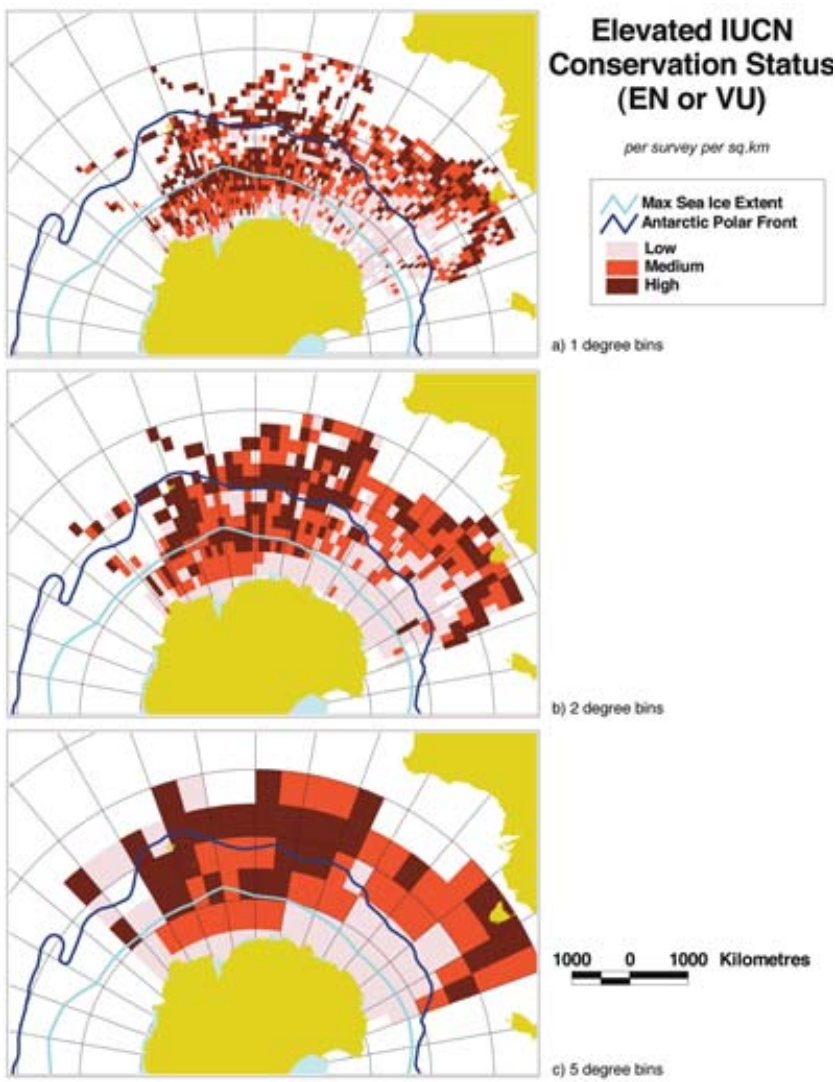

Fig. 3. Elevated IUCN Conservation Status. Distribution of seabirds with IUCN Red List categories of Endangered or Vulnerable (number of birds $/ \mathrm{km}^{2} /$ survey) at $1^{\circ} \times 1^{\circ}, 2^{\circ} \times 2^{\circ}$ and $5^{\circ} \times 5^{\circ}$ latitude $\mathrm{x}$ longitude, classified as low (pink), medium (red) and high (maroon) for the Indian sector of the Southern Ocean for the period 1977/78 to 2001/02.

values, thus displaying the highest species densities, were near Mawson and Davis (Prydz Bay). Areas surrounding the sub-Antarctic islands also tended to exhibit high concentrations, in particular around Heard Island and the McDonald Islands, and Iles Kerguelen. In contrast, the region around Macquarie Island exhibited only mediumhigh densities, reflecting the relative breeding population sizes on these islands (Chown et al. 2001, Raymond \& Woehler 2003).

\section{Seabird species richness}

The distribution of seabird species richness is illustrated in Fig. 2, and exhibited less spatial clustering than did species density. The data values for the classes of low, medium and high are presented in Table I. Generally, species richness appeared to be lower closer to the Antarctic continent, indicating a greater likelihood of species aggregations (sensu Woehler et al. 2003), not congregations, south of the maximum sea ice extent. Species richness tended from medium to high in the regions around the Antarctic Polar Front where nutrient-rich cold waters descend below

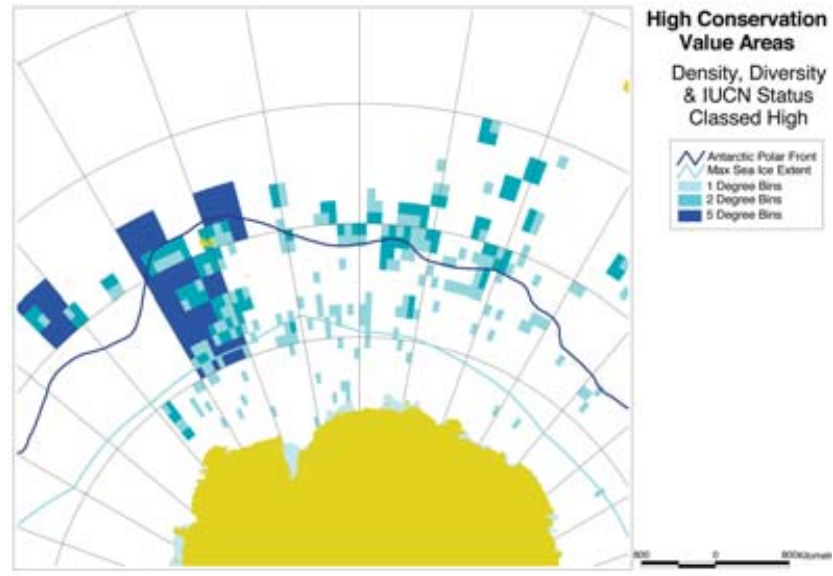

Fig. 4. High Conservation Value Areas (Density, Richness and IUCN Status Classed High). Distribution of high conservation value areas, based on their classification of high for each of species density, species richness and IUCN status (per $\mathrm{km}^{2} /$ survey) at $1^{\circ} \times 1^{\circ}$ (aqua), $2^{\circ} \times 2^{\circ}$ (jade) and $5^{\circ} \times 5^{\circ}$ (royal blue) latitude $x$ longitude for the Indian sector of the Southern Ocean for the period 1977/78 to 2001/02.

warmer waters. There is some clustering of high (and medium) species richness areas south-west of Iles Kerguelen, Heard Island and the McDonald Islands, which may be associated with proximity to breeding sites on these islands, and with foraging areas associated with the continental shelf zone or Kerguelen Plateau regions (BirdLife International 2004, Woehler et al. 2006). Some clustering of areas of medium species richness was apparent around and north of the maximum mean sea ice extent (Orsi et al. 1995), indicating that seabird species richness is likely to be greater in areas where there is access to open water. It

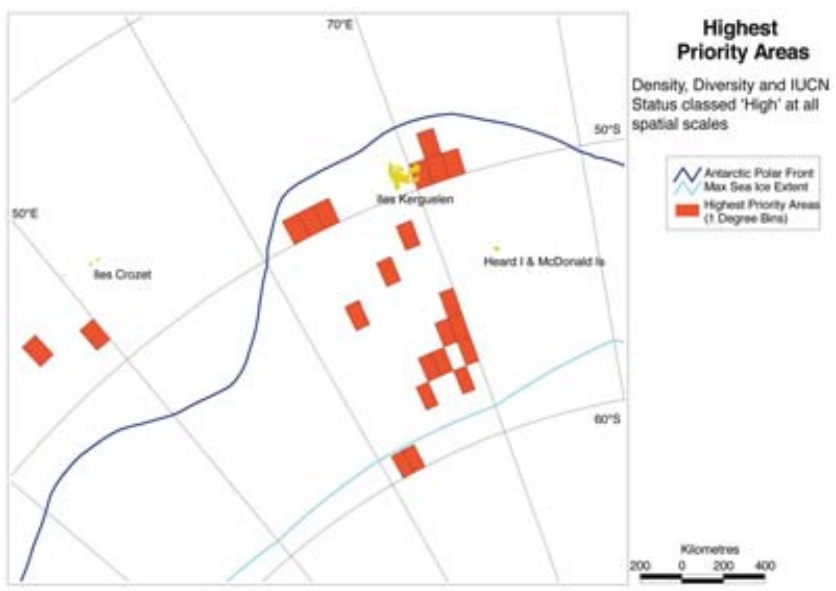

Fig. 5. Highest Priority Areas (Density, Richness and IUCN Status Classed High Across All Scales). Distribution of highest priority conservation areas (each at $1^{\circ} \times 1^{\circ}$ latitude $\mathrm{x}$ longitude), based on the overlap at all three spatial scales of high classifications for each of species density, species richness and IUCN status (per $\mathrm{km}^{2} /$ survey) for the Indian sector of the Southern Ocean for the period 1977/78 to 2001/02. 
Table I. Data summaries for species richness, species density, IUCN status and Shannon Index at $1^{\circ} \times 1^{\circ}, 2^{\circ} \times 2^{\circ}$ and $5^{\circ} \times 5^{\circ}$ bins for low, medium and high value categories.

\begin{tabular}{|c|c|c|c|c|}
\hline \multirow[b]{2}{*}{$\begin{array}{l}\text { Bin size } \\
\text { and range }\end{array}$} & \multicolumn{4}{|c|}{ Surrogate per survey per km² } \\
\hline & $\begin{array}{l}\text { Species } \\
\text { density }\end{array}$ & $\begin{array}{c}\text { Species } \\
\text { richness }\end{array}$ & $\begin{array}{l}\text { IUCN } \\
\text { status }\end{array}$ & $\begin{array}{c}\text { Shannon } \\
\text { Index }\end{array}$ \\
\hline \multicolumn{5}{|l|}{$1^{\circ}$ bins } \\
\hline Low & 0-0.097 & $0-0.071$ & $0-0.061$ & $0-0.050$ \\
\hline Medium & $0.097-0.155$ & $0.071-0.137$ & $0.061-0.199$ & $0.050-0.128$ \\
\hline High & $0.155-1$ & $0.137-1$ & 0.199-1 & $0.128-1$ \\
\hline \multicolumn{5}{|l|}{$2^{\circ}$ bins } \\
\hline Low & $0-0.175$ & $0-0.052$ & $0-0.087$ & $0-0.028$ \\
\hline Medium & $0.175-0.256$ & $0.052-0.107$ & $0.087-0.217$ & $0.028-0.074$ \\
\hline High & $0.256-1$ & $0.107-1$ & $0.217-1$ & $0.074-1$ \\
\hline \multicolumn{5}{|l|}{$5^{\circ}$ bins } \\
\hline Low & $0-0.150$ & $0-0.023$ & $0-0.175$ & $0-0.009$ \\
\hline Medium & $0.150-0.259$ & $0.023-0.064$ & $0.175-0.422$ & $0.009-0.033$ \\
\hline High & $0.259-1$ & $0.064-1$ & $0.422-1$ & 0.033-1 \\
\hline
\end{tabular}

is interesting to note that the region directly surrounding Heard Island and the McDonald Islands was characterized by low species richness while high in species density, see above.

\section{IUCN conservation status}

Proximity to the sub-Antarctic breeding islands appeared to be consistent with clustering of areas with medium to high values for IUCN status, and clustering between $70^{\circ}-115^{\circ} \mathrm{E}$ along the Antarctic Polar Front (Fig. 3). The region around Iles Kerguelen and Heard Island and the McDonald Islands was generally characterized by high values, resulting from the high number of species with elevated IUCN conservation status, in particular albatrosses and giant petrels. The region south of $60^{\circ} \mathrm{S}$ and between $100^{\circ}-160^{\circ} \mathrm{E}$ was characterized by a prevalence of low conservation status values, indicating that many species of albatrosses and petrels, currently assigned elevated IUCN conservation status, are more likely to be found farther north (see also BirdLife International 2004, 2006).

\section{Shannon Index}

The Shannon Index (also known as the Shannon-Weaver diversity index) attempts to reflect species richness and density (or distribution). In this study, the Shannon Index largely duplicated the results obtained for species richness analyses. For example, Species Richness and the Shannon Index were highly correlated at the 1 degree scale $(r=$ 0.959, $P<0.01$ ). Therefore, as a measure of both species richness and density the Shannon Index was deemed inadequate for the purposes of the current study and was not used further.

\section{High conservation value areas in the Southern Ocean}

High conservation value areas were selected by being categorised as "high" for each of the density, richness and IUCN status classing sets. Figure 4 shows High Priority Areas for the $1921^{\circ}$ bins, $2^{\circ}$ bins $(n=47)$ and $5^{\circ}$ bins $(n=$ 7 ). The key characteristics of these high conservation value areas are listed in Table II. An aggregation of bins was evident around the Antarctic Polar Front and another was present around Iles Kerguelen. The region between $60^{\circ}-70^{\circ} \mathrm{E}$, and $50^{\circ}-60^{\circ} \mathrm{S}$, south-west of Iles Kerguelen and Heard and McDonald islands, located between the Antarctic Polar Front and maximum sea ice extent, was also identified as a high conservation value area in this study.

\section{Discussion}

The aim of this study was to examine one potential process by which to identify candidate priority areas for conservation efforts in high seas areas of the Southern Ocean. However, it may not be practical or politically desirable to protect all high conservation value bins identified in this study (Fig. 4). In order to reduce the number of high conservation value bins identified for possible conservation consideration and action, a further filter was applied to these identified areas. Figure 5 shows a subset of bins, nominally the 'Highest Priority Areas' that

Table II. Species density, Species richness and IUCN Status values for $1^{\circ} \times 1^{\circ}, 2^{\circ} \times 2^{\circ}$ and $5^{\circ} \mathrm{x} 5^{\circ}$ bins classed as High based on seabirds at sea data for the Indian Ocean sector of the Southern Ocean for the period 1977/78-2001/02.

\begin{tabular}{|c|c|c|c|c|c|c|c|}
\hline & & Surveys & Null obs. & Area $\left(\mathrm{km}^{2}\right)$ & Species density & Species richness & IUCN status \\
\hline $1^{\circ}$ bins $(n=192)$ & Mean & 4.50 & & 7102 & 26.60 & 8.80 & 8.70 \\
\hline \multirow[t]{3}{*}{$2^{\circ}$ bins $(n=47)$} & Sum & 351 & 24 & 1450424 & 2167 & 552 & 761 \\
\hline & Mean & 7.50 & & 30860 & 46.10 & 11.70 & 16.20 \\
\hline & Adjusted Mean & - & - & - & 0.43 & 0.30 & 0.45 \\
\hline \multirow{2}{*}{$5^{\circ}$ bins $(n=7)$} & Mean & 27.40 & & 190644 & 143.40 & 18.70 & 41.10 \\
\hline & Adjusted Mean & - & - & - & 0.58 & 0.35 & 0.74 \\
\hline
\end{tabular}

Corresponding data values for high conservation value areas (Fig. 4), based on their classification of high for each of species density, species richness and IUCN status (per km²/survey) at $1^{\circ} \times 1^{\circ}, 2^{\circ} \times 2^{\circ}$ and $5^{\circ} \times 5^{\circ}$ latitude $x$ longitude for the Indian sector of the Southern Ocean for the period $1977 / 78$ to $2001 / 02$. 
Table III. Species density, Species richness and IUCN Status values for $1^{\circ} \mathrm{x} 1^{\circ}$ bins classed as Highest Priority Areas at all spatial scales, based on seabirds at sea data for the Indian Ocean sector of the Southern Ocean for the period 1977/78-2001/02.

\begin{tabular}{lccccrrr}
\hline $\begin{array}{l}\text { Highest } \\
\text { priority areas }\end{array}$ & Surveys & $\begin{array}{c}\text { Null } \\
\text { obs. }\end{array}$ & $\begin{array}{c}\text { Area } \\
\left(\mathrm{km}^{2}\right)\end{array}$ & $\begin{array}{r}\text { Species } \\
\text { density }\end{array}$ & $\begin{array}{r}\text { Species } \\
\text { richness }\end{array}$ & $\begin{array}{r}\text { status } \\
\text { stan }\end{array}$ \\
\hline $1^{\circ}$ bins & Sum & 57 & 6 & 162981 & 424.00 & 179.00 & 40.03 \\
$n=22$ & Mean & 2.59 & & 7408 & 19.27 & 8.14 & 1.82 \\
\multicolumn{2}{r}{ Adjusted Mean } & - & - & - & 0.27 & 0.47 & 0.51 \\
\hline
\end{tabular}

were selected on the basis that they were characterized by 'high' values for the density, richness, and IUCN status classing sets at all three spatial scales of $1^{\circ}, 2^{\circ}$ and $5^{\circ}$, Table III. For practical purposes, these highest priority areas are mapped and described at the $1^{\circ}$ bin size $(n=22)$, (Fig. 5). There appears to be a strong relationship between the location and bathymetry of the Kerguelen Plateau and the locations of these highest priority areas. Previous studies have found a relationship between oceanographic features and wildlife distributions, (e.g. Bradshaw et al. 2004, Woehler et al. 2006). A clustering of four bins is apparent immediately east of Iles Kerguelen, and again a larger aggregation of high conservation value bins is apparent south-west of Heard Island and the McDonald Islands. The combination of feeding areas proximal to large breeding populations is likely the primary cause of these clusters.

All of the high conservation value areas and highest priority areas identified in this study are worthy of consideration for conservation efforts based upon their species richness, species density and IUCN status of the species observed within them. Further, protection of these areas is warranted as the Kerguelen Plateau is known to be particularly rich in marine living resources (i.e. seabird prey species) that aggregate over the nutrient rich continental shelf zone, and the area is subject to high levels of fishing particularly Illegal, Unregulated and Unreported fishing (IUU: Constable et al. 2000, Gjerde \& Breide 2003, Lea \& Dubroca 2003).

Designating the identified high conservation value or highest priority areas will not and cannot unequivocally protect the biodiversity in the study area, as the seabird atsea sightings used here are simply a surrogate for the marine biodiversity of the region, and their potential to identify key sites for conservation consideration. However, there is evidence to suggest that sites with similar high conservation value for birds do correspond with important sites for other species (Brooks et al. 2001, Garson et al. 2002, Dallmeyer 2003). For example, Garson et al. (2002) found that selecting sites that contained 10 observations of particular bird species incorporated $87 \%$ of all at-risk species considered in their study. Information on other, non-seabird species in the Southern Ocean is not geographically comprehensive or representative, or as complete as seabirds at-sea, but decisions regarding the conservation and management of the high seas need to be made now. The use of seabirds as surrogates is an internationally recognized approach for the identification of potential candidate sites for protection (e.g. Important Bird Areas: IBAs) which can also often protect sites important for other species. Brooks et al. (2001) compared IBA performance for conservation to simple greedy complementarity ${ }^{1}$. Brooks et al. (2001) found that over $90 \%$ of terrestrial vertebrates, mammals and birds were represented within the IBA network but required substantially less data than that required by the complementarity method, which missed three key sites for birds. The shared characteristics of the highest priority areas identified in this study appear to include proximity to subAntarctic islands/breeding sites, the Antarctic Polar Front, and access to open water. The areas around Iles Kerguelen and south-west of Heard Island and the McDonald Islands appear the most important in the study area. These areas correspond with areas prioritised as potential pilot MPAs at the 2003 Malaga high seas MPA workshop (Gjerde \& Breide 2003), and correspond with areas identified by BirdLife International $(2004,2006)$ as important areas for albatrosses and petrels in terms of foraging and proximity to breeding sites on sub-Antarctic islands. Furthermore, the areas around Iles Kerguelen, Heard Island and the McDonald Islands are particularly vulnerable due to high levels of IUU fishing in the region (Gjerde \& Breide 2003).

The preliminary exploration of the use of seabirds as surrogates in this study has enabled the identification of candidate sites for conservation action in the Indian sector of the Southern Ocean. However, many of the identified sites are actually within shallow oceanic areas, sometimes within national jurisdiction. Clearly the approach adopted in this study alone will not be sufficient to identify a comprehensive network of high seas MPAs within the Southern Ocean. With this in mind, further research is warranted elsewhere within the Southern Ocean, such as, but not limited to, considering the application of complementarity methods for the selection of sites in the Southern Ocean, or environmental domains analysis (Margules et al. 2002, ATCM XXVIII 2005).

This study cannot claim to be a comprehensive assessment of areas for biodiversity conservation in the Indian Ocean sector of the Southern Ocean. The sites identified here could form one basis for the selection of MPAs, but clearly there will be other approaches and additional analyses possible when other data sets become available. Seabird sightings have been demonstrated to be a useful surrogate for marine biodiversity in the Southern

\footnotetext{
${ }^{1}$ Simple greedy complementarity aims to identify a minimum network of sites that contains at least one representation of each species identified within the overall area. Species abundance is not taken into account as the method simply selects the site containing the most species, and then chooses the next site containing the most unrepresented species, repeating the process until all species are represented. Complementarity requires ample data to be available on multiple species.
} 
Ocean, and should be incorporated into any efforts to identify a system of Southern Ocean MPAs, including the CCAMLR Bioregionalisation program now underway (Grant et al. 2006). However, as the present study has not identified many high-seas areas (rather, it identified shallow pelagic areas under national jurisdiction or in the continental shelf zone), it is essential that data on other marine species, environmental and abiotic data be included when these data become available. As a minimum, it is recommended that the Highest Priority Areas be accorded the highest priority for consideration as pilot MPAs until such time that other datasets are available (for example, on the distribution and abundance of other species such as marine mammals in the Southern Ocean). The growing recognition of the precautionary approach for marine protection supports this tactic.

\section{Acknowledgements}

The authors acknowledge the support of the Antarctic Climate and Ecosystems CRC funded through the Australian Government's Cooperative Research Centres Programme. The seabird at sea data were collected under ASAC Project 2208 led by E.J. Woehler. We thank all observers for collecting these data under typically difficult conditions. Thanks also to Lee Belbin for assistance with technical aspects of the study, and to our reviewers whose comments significantly improved the paper.

\section{References}

Ainley, D.G., RibIC, C.A. \& SPEAR, L.R. 1993. Species-habitat relationships among Antarctic seabirds: a function of physical or biological factors? Condor, 95, 806-816.

ATCM XXVIII / WP02. 2005. Systematic Environmental Protection in Antarctica: a draft systematic environmental-geographic framework for Antarctica created using Environmental Domains Analysis. ATCM XXVII / Working Paper (WP02), submitted by New Zealand.

BirdLife InternationaL. 2004. Tracking ocean wanderers: the global distribution of albatrosses and petrels. Paper presented to Results from the Global Procellariiform Tracking Workshop, 1-5 September, 2003, Gordon's Bay, South Africa. Cambridge, UK: BirdLife International, 116 pp.

BirdLife InTERNATional 2006. Analysis of albatross and petrel distribution within the CCAMLR convention area: results from the global Procellariiform tracking database. CCAMLR Science, 13, 143-174.

Bradshaw, C.J.A., Higgins, J., Michael, K.J., Wotherspoon, S.J. \& HINDELL, M.A. 2004. At-sea distribution of female southern elephant seals relative to variation in ocean surface properties. ICES Journal of Marine Science, 61, 1014-1027.

Brooks, T., Balmford, A., Burgess, N., Hansen, L.A., Moore, J., RahbeK, C., Williams, P., Bennun, L.A., Byaruhanga, A., Kasoma, P., NJoroge, P., Pomeroy, D. \& Wondafrash, M. 2001. Conservation priorities for birds and biodiversity: do East African Important Bird Areas represent species diversity in other terrestrial vertebrate groups? Ostrich, Supplement 15, 3-12.
CCAMLR. 2005. Marine Protected Areas in the Context of CCAMLR. A Management Tool for the Southern Ocean. CCAMLR Marine Protected Areas (MPA) Workshop, Silver Spring, Maryland, USA. 29 August-1 September 2005. WS-MPA-05/4.

Chown, S.L., Rodrigues, A.S.I., Gremmen, N.J.M. \& GASton, K.J. 2001. World Heritage status and the conservation of Southern Ocean islands. Conservation Biology, 15, 550-557.

Constable, A.J., de la Mare, W.K., Agnew, D.J., Everson, I. \& Miller, D. 2000. Managing fisheries to conserve the Antarctic marine ecosystem: practical implementation of the Convention on the Conservation of Antarctic Marine Living Resources (CCAMLR). ICES Journal of Marine Science, 57, 778-791.

Dallmeyer, D.G. ed. 2003. Values at sea: ethics for the marine environment. Athens, GA: University of Georgia Press, 293 pp.

Garson, J., Aggarwal, A. \& Sarkar, S. 2002. Birds as surrogates for biodiversity: an analysis of a data set from southern Québec. Journal of Biosciences, 27, 247-360.

GJerde, K.M. \& Breide, C., eds. 2003. Towards a strategy for High Seas Marine Protected Areas. Proceedings of the IUCN, WCPA and WWF Experts Workshop on High Seas Marine Protected Areas, 15-17 January 2003, Malaga, Spain. Gland, Switzerland: IUCN.

Grant, S., Constable, A., Raymond, B. \& Doust, S. 2006 Bioregionalisation of the Southern Ocean. Report of Experts Workshop, Hobart, September 2006. WWF-Australia and ACE CRC, 45 pp.

HarRIS, J.W. 2006 The Madrid Protocol and beyond: strategies for marine conservation in the high seas and Southern Ocean. $\mathrm{PhD}$ thesis, University of Tasmania, xvi +220 pp. [Unpublished].

HuNT, G.L. 1991. Occurrence of polar seabirds at sea in relation to prey concentrations and oceanographic factors. Polar Research, 10, 553-559.

Kelleher, G., Bleakley, C. \& Wells, S. 1995. A global representative system of marine protected areas, vol. 1. Antarctic, Arctic, Mediterranean, Northwest Atlantic, Northeast Atlantic and Baltic. Great Barrier Reef Marine Park Authority (Australia), World Bank, Washington, DC: IUCN, 262 pp.

LeA, M.A. \& Dubroca, L. 2003. Fine-scale linkages between the diving behaviour of Antarctic fur seals and oceanographic features in the southern Indian Ocean. ICES Journal of Marine Science, 60, 990-1002.

Margules, C.R., Pressey, R.L. \& Williams, P.H. 2002. Representing biodiversity: data and procedures for identifying priority areas for conservation. Journal of Biosciences, 27, 309-26.

Orsi, A.H., Whitworth, I. \& Nowlin, W.D.J. 1995. On the meridional extent and fronts of the Antarctic Circumpolar Current. Deep-Sea Research, 42, 641-673.

Raymond, B. \& Woehler, E.J. 2003. Predicting seabirds at sea in the Southern Indian Ocean. Marine Ecology Progress Series, 263, 275-85.

SALA, E. \& Knowlton, N. 2006. Global marine biodiversity trends. Annual Review of Environment and Resources, 31, 93-122.

Watts, D. \& Woehler, E.J. 2003. Wildlife on Voyage Database. Australian Antarctic Data Centre - SnoWhite Metadata (http://www.aad.gov.au/default.asp?casid=3802). Antarctic Division, Australia.

WoEHLER, E.J. 1990 The distribution of seabird biomass in the Australian Antarctic Territory: implications for conservation. Environmental Conservation, 17, 256-261.

WoEHLER, E.J. 1997. Seabird abundance, biomass and prey consumption within Prydz Bay, Antarctica, 1980/81-1992/93. Polar Biology, 17, 371-383.

Woehler, E.J., Raymond, B. \& Watts, D. 2003. Decadal-scale seabird assemblages in Prydz Bay, East Antarctica. Marine Ecology Progress Series, 251, 299-310.

Woehler, E.J., Raymond, B. \& Watts, D.J. 2006. Convergence or divergence: where do short-tailed shearwaters forage in the Southern Ocean? Marine Ecology Progress Series, 324, 261-270. 